\title{
Phytoremediation Potential of Phragmites Karka For Arsenic Contaminated Soil And Water
}

\author{
${ }^{1}$ Anjali Verma, ${ }^{2}$ Ashok Ghosh ${ }^{3}$ Mamta Kumari, ${ }^{4}$ Namita Dhusia and \\ ${ }^{5}$ Nandkishor More* \\ ${ }^{1,3,4,5}$ Department of Environmental Science, Babasaheb Bhimrao Ambedkar University (A Central University), \\ Lucknow-226025, (U.P.), India. \\ ${ }^{2}$ Department of Environment and Water Management, A. N. College, Patna - 80001, INDIA.
}

\begin{abstract}
Contamination of soils, groundwater, sediments, surface water, and air with hazardous and toxic chemicals is one of the major problems facing the industrialized world today. Contaminated land and water generally result from past industrial activities when awareness of the health and environmental effects connected with the production, use, and disposal of hazardous substances were less well recognized than today. Heavy metals are a dangerous group of soil and water pollutants.Among heavy metals $\mathrm{Pb}, \mathrm{Cd}$ and As are considered potentially important environmental pollutants due to their trends to accumulate on vital organs of humans and animals. Sources of metals include domestic and industrial effluents, the atmosphere, runoff and lithosphere.Chronic problems associated with heavy metal exposure may range from intermediate poisonings to death. Arsenic is the most prevalent toxic heavy metal that is present in the environment both naturally and due to certain human activities. Apart from its natural occurrence it is also released into the environment through burning fossil fuels, paper production, cement manufacturing and mining activities.The toxicity and redistribution of arsenic in the environment make it evoking public concern. Therefore swift removal of metals such as arsenic from contaminated sites is of foremost importance. Several bioremediation technologies are existing for the remediation of As from contaminated soil and water.Phytoremediation is a part of bioremediation process which takes advantage of the natural processes of plants. Aquatic macrophytes can be a good tool for the remediation of arsenic-contaminated aquatic systems and some experiments have been designed to remove as include wetland systems. Wetlands was designed and constructed five pots were planted at difference concentration and provided with one month stabilization period to determine bioremediation potential of the aquatic plant Phragmiteskarka in arsenic contaminated soil and water.The study suggests about the behavior of Phragmiteskarka alone with reference to tolerance of Arsenic containing solution was not uniform. It was observed that other concentration of 1400ppb was intolerable to test plant and the toxicity became very severe toxicity, led to death of the test plant.
\end{abstract}

Keywords: Arsenic, Aquatic plant, Contamination, Heavy Metals, Phragmites karka. Phytoremediation, Pollution.

\section{Introduction}

The quality of life on Earth is linked inextricably to the overall quality of the Environment. Contaminated lands and water generally result from past industrial activities when awareness of the health and environmental effects connected with the production, use, and disposal of hazardous substances were less well recognized than today. The problem is worldwide, and the number of contaminated sites was estimated by (cairney, 1993).The problems associated with contaminated sites now assume increasing prominence in many countries. It is now widely recognized that contaminated sites is a potential threat to human health, and its continual discovery over recent years has led to international efforts to remedy many of these sites, either as a response to the risk of adverse health or environmental effects caused by contamination or to enable the site to be redeveloped for use. There has been a tremendous growth of industries worldwide in the last few decades and the associated anthropogenic activities have often resulted in environmental pollution.Heavy metals such as As, $\mathrm{Cr}, \mathrm{Pb}$ etc. are prominentcomponents of industrial effluents which are discharged in to the environment and consequently pollute the ecosystem. The presence of these heavy metals in the environment has been a subject of great concern due to their toxicity, non-biodegradable nature and the long biological half-lives for their elimination from biological tissues (Olatunji et al, 2009).Exposure to heavy metals through ingestion, inhalation, or skin contact is usually chronic due to food chain transfer. Arsenic contamination in ground water and other segments in many areas of downstream Himalayas is mainly due to fluvial deposits, mainly of Holocene age and later due to extraction of ground water. Arsenic is used in industry as a wood preservative and in paints, dyes, metals, soaps, insecticides and semi-conductors. Apart from its natural occurrence it is also released into the environment through burning fossil fuels, paper production, cement manufacturing and mining activities. Arsenic contamination in water has posed severe health problems around the world. Some 
technologies that have been used are high-temperature incineration and various types of chemical decomposition (e.g., base-catalyzed dechlorination, UV oxidation). They can be very effective at reducing levels of a range of contaminants, but have several drawbacks, principally their technological complexity, the cost for small-scale application, and the lack of public acceptance, especially for incineration that may increase the exposure to contaminants for both the workers at the site and nearby residents. The need to remediate these sites has led to the development of new technologies that emphasize the destruction of the pollutants rather than the conventional approach of disposal.

\subsection{Heavy Metal Accumulation in water}

Discharges of inorganic and organic micro-pollutants and radioactivity from various industrial, agricultural and municipal sources have resulted in permanently contaminated water, polluted sediments and the accumulation of chemicals in the aquatic food-chain.

\subsection{ArsenicContamination}

Arsenic is used in industry as a wood preservative and in paints, dyes, metals, soaps, insecticides and semi-conductors. It is the 20th abundant element in earth crust (Woolson et al,1975), 22nd in seawater (Brown et al ,1991) and 12th in the human body (Mandal and Suzuki, 2002). It is now well recognized that consumption of arsenic, even at low levels, leads to carcinogenesis (Mandal and Suzuki, 2002). Although the occurrence of arsenic in the environment is mainly from minerals and geogenic sources, human activities such as mining, burning of fossil fuels, use of arsenic containing chemicals in agriculture also cause arsenic distribution in the environment (Bissen and Frimmel, 2003). The areas throughout the world that have the worst documented contamination of groundwater by arsenic are in South Asia and the toxin poses a frequent problem in Nepal, India and Bangladesh. Indiscriminate use of arsenical pesticides during the early to mid-1900s led to an extensive contamination of soil (Smith et al, 1998). A large number of sites worldwide have been contaminated by arsenic from natural and anthropogenic sources (Mandal and Suzuki, 2002). Many countries, especially Taiwan, Argentina, India, Bangladesh, Mexico, Hungary, and Chile, have reported extensive arsenic contamination of their groundwater supplies (Smedley, 2002; Nikolaidis et al, 2004).Elevated levels of arsenic in agricultural soil could pose a serious threat to plants and human health and the environment through the food chain pathways (Bruce et al, 2003; Duxbury et al, 2003). Arsenic toxicity depends on its speciation, and generally inorganic arsenic species are more toxic than those of organic species (Meharg and Hartley-Whitaker, 2002; Ng, 2005)

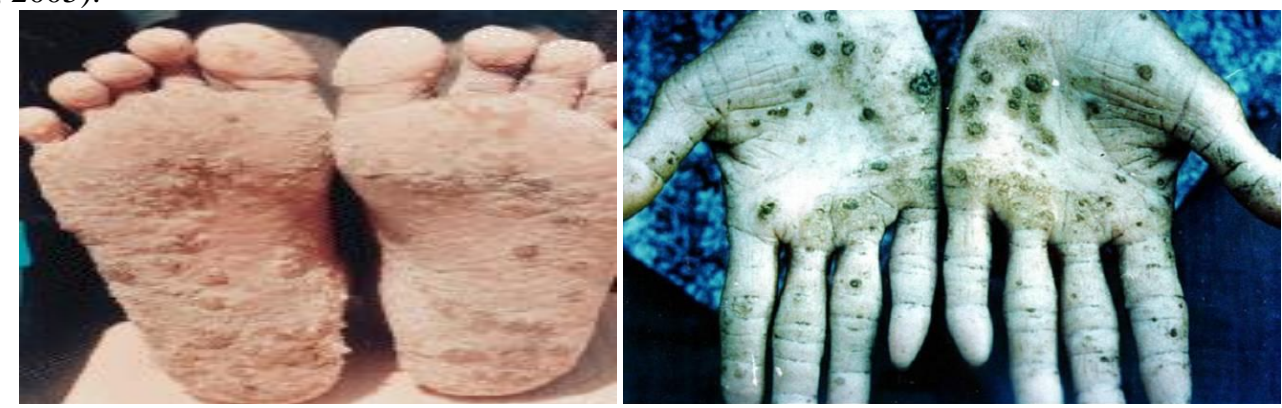

Fig 1.Lesions of arsenic

\subsection{General Remediation Approach}

Several technologies exist for the remediation of metals-contaminated soil and water. These technologies are contained within five categories of general approaches to remediation: isolation, immobilization, toxicity, reduction, physical separation and extraction. These are the same general approaches used for many types of contaminants in the subsurface (La Grega et al, 1994).

\subsection{Bioremediation}

Itis an option that offers the possibility to destroy or render harmless various contaminants using natural biological activity. Itis the technology that uses microorganism metabolism to remove pollutants it uses relatively low-cost, low-technology techniques, which generally have a high public acceptance and can often be carried out on site. It is defined as the process whereby organic wastes are biologically degraded under controlled conditions to an innocuous state, or to levels below concentration limits established by regulatory authorities (Flathman et al, 1993). By definition, bioremediation is the use of living organisms, primarily microorganisms, to degrade the environmental contaminants into less toxic forms. It uses naturally occurring bacteria and fungi or plants to degrade or detoxify substances hazardous to human health and/or the environment. Most bioremediation systems are run under aerobic conditions, but running a system under anaerobic conditions (Muelle et al, 1996) may permit microbial organisms to 
degrade otherwise recalcitrant molecules. Rapid advances in the last few years have helped us in the understanding of process of bioremediation. The use of culture independent molecular techniques has definitely helped us to understand the microbial community dynamics, structure and assisted in providing the insight in to details of bioremediation which has surely facilitated to make the technology safer and reliable. The first patent for a biological remediation agent was registered in 1974, being a strain of Pseudomonas putida (Prescot et al, 2002) Microorganisms used to perform the function of bioremediation are known as bioremediators (Terranovabiosystems.com, 2009). As such, it uses relatively low-cost, lowtechnology techniques, which generally have a high public acceptance and can often be carried out on site.

\subsection{Factors of bioremediation}

The control and optimization of bioremediation processes is a complex system of many factors. These factors include: the existence of a microbial population capable of degrading the pollutants; the availability of contaminants include: the existence of a microbial population capable of degrading the pollutants; the availability of contaminants to the microbial population; the environment factors (type of soil, temperature, $\mathrm{P}^{\mathrm{H}}$, the presence of oxygen or other electron acceptors, and nutrients).

\subsection{Bioremediation strategy:}

Different techniques are employed depending on the degree of saturation and aeration of an area.

\subsubsection{In situBioremediation:}

In situ techniques are defined as those that are applied to soil and groundwater at the site with minimal disturbance. These techniques (Shukla et al, 2010; Bouwer\&Zehnder, 1993) are generally the most desirable options due to lower cost and fewer disturbances since they provide the treatment in place avoiding excavation and transport of contaminants treatment is limited by the depth of the soil that can be effectively treated.

\subsubsection{Ex situBioremediation:}

Inthese techniques involve the excavation or removal of contaminated soil from ground. Composting is a process by which organic wastes are degraded by microorganisms, typically at elevated temperatures. Typical compost temperatures are in the range of $55^{\circ}$ to $65^{\circ} \mathrm{C}$. The increased temperatures result from heat produced by microorganisms during the degradation of the organic material in the waste. Windrow composting has been demonstrated using the following basic steps. First, contaminated soils are excavated and screened to remove large rocks and debris.

\subsection{Phytoremedition}

It isthe use of plants to extract, sequester, and/or detoxify pollutants, has been reported to be an effective, non-intrusive, inexpensive, aesthetically pleasing, socially accepted technology to remediate polluted soils (Alkorta\&Garbisu, 2001; Weber et al, 2001; Garbisuet al, 2002). Within the field of phytoremediation, different categories have been defined such as, among others, phytoextraction, phytofiltration (rhizofiltration, blastofiltration), phytostabilization, phytovolatilization, phytodegradation (phytotransformation), plant-assisted bioremediation (plant-assisted degradation, plant-aided in situ biodegradation, phytostimulation, enhanced rhizosphere degradation, rhizodegradation).Phytoremediation is widely viewed as the ecologically responsible alternative to the environmentally destructive physical remediation methods currently practiced (Meagher, 2000).In the last few years, some excellent reviews have been published focusing on different aspects of phytoremediation (Salt et al, 1995a, 1998; Chaney et al, 1997; Raskin et al, 1997; Wenze et al, 1999; Meagher, 2000; Navari- Izzo\&Quartacci, 2001; Lasat, 2002; McGrath et al, 2002; McGrath\&Zhao, 2003; McIntyre, 2003; Singh et al, 2003).Plants for phytoextraction, i.e., metal removal from soil, should have the following characteristics: (i) tolerant to high levels of the metal, (ii) accumulate reasonably high levels of the metal, (iii) rapid growth rate, (iv) produce reasonably high biomass in the field, and (v) profuse root system (Garbisu et al, 2002). The idea of using plants to remediate metal polluted soils came from the discovery of "hyper accumulators' 


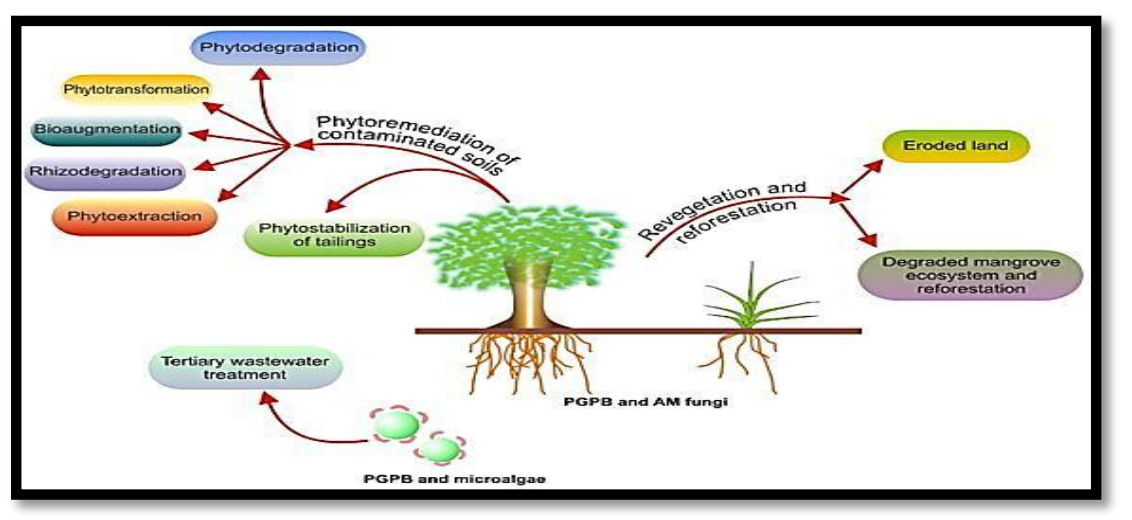

Fig 2. Phytoremediation process

1.8Plant Processes: Phytoremediation takes advantage of the natural processes of plants. These processes include water and chemical uptake, metabolism within the plant, exudates release into the soil that leads to contaminant loss, and the physical and biochemical impacts of plant roots. Growth of plants depends on photosynthesis, in which water and carbon dioxide are converted into carbohydrates and oxygen, using the energy from sunlight. Roots are effective in extracting water held in soil, even water held at relatively high matrix and osmotic negative water potentials; extraction is followed by upward transport through the xylem. Transpiration (water vapor loss from plants to the atmosphere) occurs primarily at the stomata (openings in leaves and stems where gas exchange occurs), with additional transpiration at the lenticels (gas exchange sites on stem and root surfaces).

\subsection{Phytoremediation of arsenic using macrophytes:}

Phytoremediation of the toxic contaminants can be readily achieved by aquatic macrophytes or by other floating plants sincethe process involves biosorption and bioaccumulation of the soluble and bioavailable contaminants from water As (V) is the predominant species in the toxic water, and As (V) and As (III) are bioavailable forms for the aquatic plants (Sizova et al, 2002).

\subsection{Constructed wetland approach for removal of Arsenic:}

To remove As from potential drinking water sources, a variety of conventional and non-conventional technologies have been studied, and these technologies have been reviewed by several authors (Mohan and Pittman, 2007). However, it is known that conventional engineered treatment technologies are costly and create problems of sludge generation and disposal (Kosolapov et al, 2004; Cohen et al, 2006; Nelson et al, 2006). In addition, these systems often become sources of As-rich effluents and are typically located in remote isolated areas (such as mining sites), thus precluding the transportation of the effluents to large centralized treatment facilities.Constructed wetlands are low-energy 'green' systems that havebeen increasingly applied in wastewater treatment since the mid-1980s (Sun and Saeed, 2009).Currently, the applications of wetland systems are mostlyin the treatment of domestic sewage, especially in rural areas in developed countries in Europe and the USA (Coope et al, 1996;Scholz and Lee, 2005; Kadlec and Wallace, 2009). Constructed wetlands have considerable potential to remove metals and metalloids, including arsenic (Ye et al, 2003; Buddhawong et al, 2005).

\subsection{Plant species -Phragmiteskarka:}

For the bioremediation process plant (Phragmiteskarka) was used.In this we made use of this aquatic plant in the constructed wetland for arsenic contaminated water to check its accumulation, tolerance and remediating capacity in soil arsenic.Phragmiteskarkais an emergent aquatic weed. It is promising emergent macrophytes for sustainable use in wastewater treatment due to its rapid growth.Tall Reed is a perennial reed, with creeping rhizomes. Culms are erect, up to $10 \mathrm{~m}$ tall. Leaf-blades are $30-80 \mathrm{~cm}$ long and $1.2-4 \mathrm{~cm}$ wide, hairless, rough to touch beneath, the tips flat and stiff (occasionally almost smooth or with thread-like tips).Flowers are borne in panicles 30-50 cm long, 10-20 cm wide, the lowest node often many-branched in a whorl, brownish purple. Rhachilla, long, silky hairy above the lowest lemma. The branches bare of spikelets for some distance from their base. Spikelets are 9-12 mm long, the rhachilla-hairs 4-7 $\mathrm{mm}$ long, rather sparse; lower glume just over half as long as the upper; upper glume narrowly elliptic to very narrowly elliptic, 4-6 mm long, acute to sub acute; lowest lemma very narrowly elliptic, $7.5-12 \mathrm{~mm}$ long; fertile lemmas very narrowly lanceolate, $85-11 \mathrm{~mm}$ long. Flowering:April-November.The contaminated water was treated with Phragmiteskarkausing phytofiltrationtechnology.Objectives of the study were to determine the bioremediation 
potential of the Phragmiteskarka in arsenic contaminated soil and water. To determine its tolerance potential and also to check the comparative remediation efficacy of aquatic plant Phragmiteskarka.

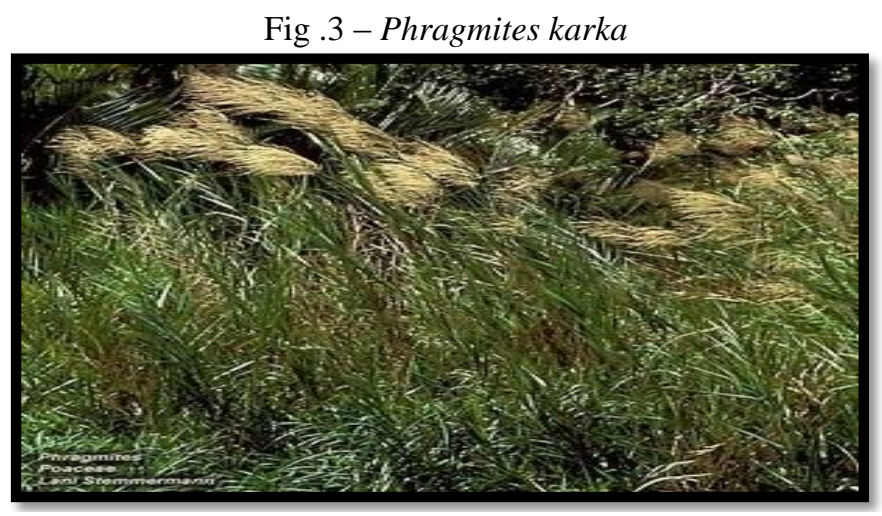

\subsection{EXPERIMENTAL DESIGN}

\section{Materials And Methods}

A field study was conducted in the experimental gardenfor the period of one month to study the arsenic remediation. Pot (length $22 \mathrm{~cm}$ ) was used for growing the plant. The experiment was conducted under completely randomized design and $9 \mathrm{~kg}$ of the garden soil was filled inpot. Pot was labelled according to arsenic concentration.

Fig. 4. Structure of constructed wetland unit

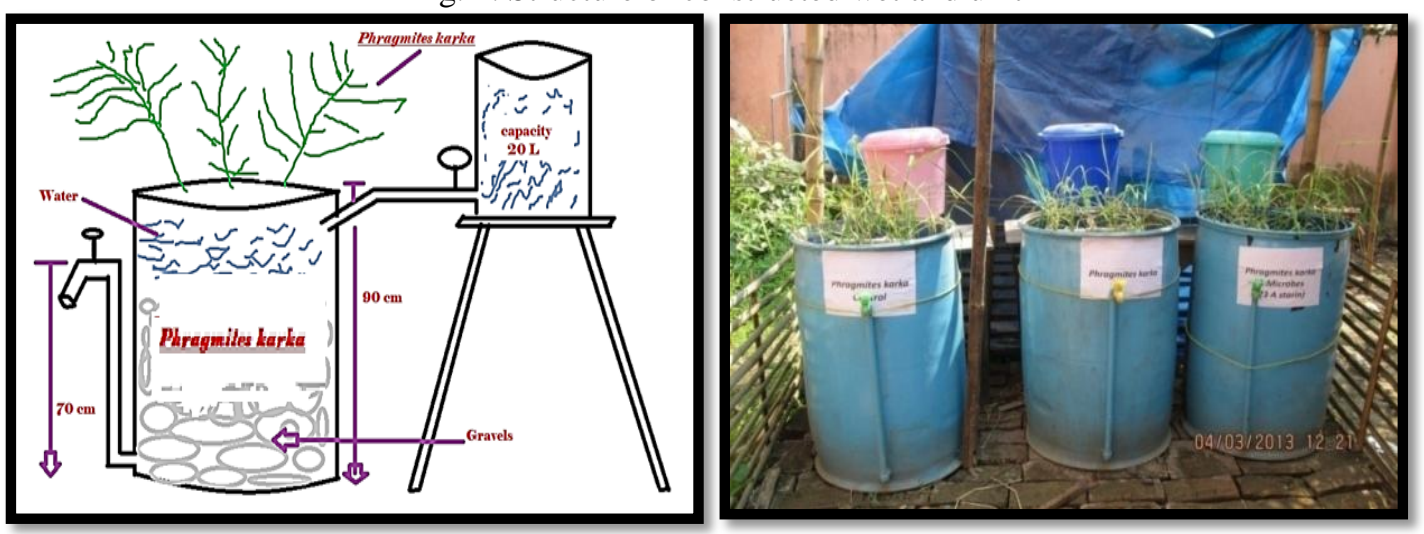

In this a tank of capacity 60 litres and this tank was filled with water and another tank of 20litre capacity was connected with a pipe so that water can flow through the tank (Please see diagram 1) as shown. Here 72 hrs of retention period was provided for it action.

\subsubsection{Constructed details:}

Height of wetland was $90 \mathrm{~cm}$, Radius of wetland $30 \mathrm{~cm}$,Capacity of water tank was $20 \mathrm{~L}$, height of outlet from bottom $70 \mathrm{~cm}$ and Filter media was porous gravel.

\subsection{Sample collection:}

For plant inflow and outflow sample were collected after 72 hrretention period and preserved with 50\% HCL.

\subsection{Experimental procedure:}

Constructed wetland was made in 3 units - in first unit control used only Phragmiteskarka was used with simple tap water, in second unit Phragmiteskarka was used with synthetic water of different concentration and third unit was prepared with Phragmiteskarkawith microbes, then different concentration of synthetic water was used. Influent of different concentration was poured and after 3 days retention period effluent was collected and preserved with 50\%HCL.Five pots were planted with Phragmiteskarka at difference concentration and provided with one month stabilization period. 


\subsubsection{Chemical analysis: Preparation of plant sample}

In the laboratory, the sample separated into leaves, stem and the roots. They were then thoroughly washed with tap water, rinsed three times with distilled water and, for analysis of the elements, dried in an oven at $70^{\circ} \mathrm{C}$ for $10 \mathrm{~h}$. To obtain the dry weight, they were ground to a fine powder and then digested with nitric acid. The digestion temperature was controlled at 80-100degree centigrade to avoid Arsenic volatilization.

\subsubsection{Testing of arsenic in the water and soil sample:}

There are number of methods available to identify and determine total arsenic, Arsenide and arsenate. Unpolluted freshwater normally does not contain organic compounds, but may contain inorganic arsenic compounds in the form of arsenate and Arsenite.SDDC method was used with UV-spectrophotometer for the testing of arsenic contaminated sample in which arsine gas is generated in acidic solution, is applicable to the determination of total inorganic arsenic when interferences are absent and when the sample contains no methyl arsenic compounds.

\subsubsection{Principle:}

Arsenic in presence of $\mathrm{Zn}$ in acid medium gets reduced to arsine gas, AsH3 then it was passed through a scrubber tube containing glass wool soaked with lead acetate, and later absorbed in silver diethyldithicarbomate dissolved in pyridine. Arsenic reacts with the silver salt to form a red complex which can be determined calorimetrically. Many other metals such as $\mathrm{Cr}, \mathrm{Co}, \mathrm{Cu}, \mathrm{Hg}, \mathrm{Mo}, \mathrm{Ni}, \mathrm{Pt}, \mathrm{Sb}$ and $\mathrm{Ag}$ interfere in the detection of As, but the concentration of these metals normally encountered in the waters are often less to produce any significant interference.

\subsection{Procedure:}

$35.0 \mathrm{ml}$ sample was took into the arsenic generator and $5 \mathrm{ml}$ conc. $\mathrm{HCl}, 2 \mathrm{ml} \mathrm{KI}$ solution, and $0.4 \mathrm{ml}$ (8drops) $\mathrm{SnCl}_{2}$ reagent thoroughly mixed the sample after addition. Keptfor about 15 minutes.Soaked the glass wool in scrubber with lead acetate solution taking care that the solution should not drain into the generator. Then $5 \mathrm{ml}$ Silver dithyldithiocarbamat reagent (SDDC)solution was took in the absorber tube then $3 \mathrm{gm}$ Znaddedin the generator and immediately connect the assemble with all the joints air tight.Solution was Kept for about 30 minutes, for the generation of arsine with slight heating of the generator.Remove solution from the absorber and the intensity of the color was measured at the $535 \mathrm{~nm}$ using the reagent blank as a reference.

\section{Results And Disscussion}

All the results are shown below in the form of tables and Graphs:

3.1 Table showing result of water sample of Phragmiteskarka

\begin{tabular}{|c|c|c|}
\hline $\begin{array}{l}\text { Provided } \\
\text { Conc.(ppb) }\end{array}$ & $\begin{array}{c}\text { Control } \\
\text { (ppb) }\end{array}$ & Effluent(Phragmiteskarka)(ppb) \\
\hline 500 & 6 & 15 \\
\hline 600 & 8 & 17 \\
\hline 700 & 8 & 46 \\
\hline 800 & 10 & 79 \\
\hline 900 & 10 & 37 \\
\hline 1000 & 9 & 59 \\
\hline 1100 & 8 & 71 \\
\hline 1200 & 9 & 76 \\
\hline 1300 & 10 & 89 \\
\hline 1400 & 9 & 91 \\
\hline
\end{tabular}

3.2 Graph showing different concentration of Arsenic

\section{Effluent (Phragmites karka)}

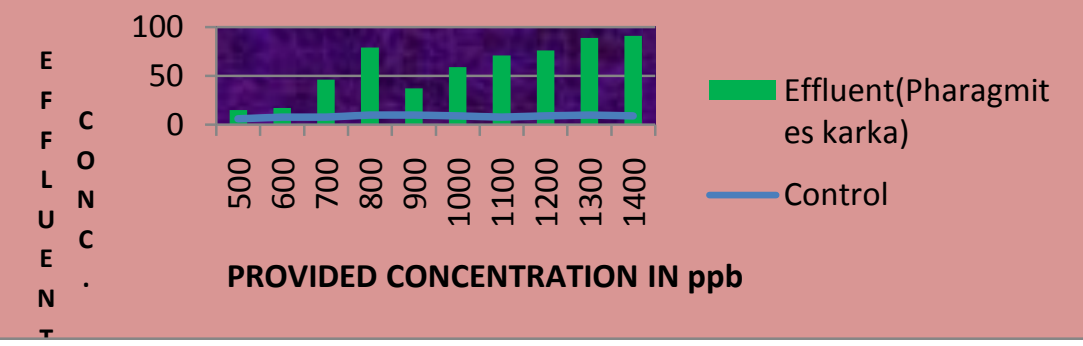


This result shows (Please see graph 3.2) that after providing different concentration of Arsenic, the uptake of arsenic by Phragmiteskarka revealed a sharp decrease up to $800 \mathrm{ppb}$. After some time interval the plant stabilizes and its defense mechanism starts working leading to increased accumulation of arsenic up to 1400 $\mathrm{ppb}$. The plants developedresistant capacity against arsenic toxicity. However as it continued to at very high concentration beyond $1500 \mathrm{ppb}$, the arsenic toxicity becomes severe leading to death of the plants. In these experimenttwo peak values of arsenic accumulation at $600 \mathrm{ppb}$ and $900 \mathrm{ppb}$ was observed.It has been found that when the different concentration of arsenic solution is provided to test plant, the accumulation of Arsenic by test plant within the tolerance limit. Hence it is concluded that Phragmiteskarka was able to tolerate As concentration of $1400 \mathrm{ppb}$.

Table 3.3 Accumulation of arsenic in in Phragmiteskarka

\begin{tabular}{|c|c|c|}
\hline $\begin{array}{c}\text { Provided } \\
\text { conc. (ppb) }\end{array}$ & $\begin{array}{c}\text { plant } \\
\text { accumulation(pp) }\end{array}$ & $\begin{array}{c}\text { plant } \\
\text { \%accumulation }\end{array}$ \\
\hline control & 0 & 0 \\
\hline 500 & 162 & 32 \\
\hline 600 & 86 & 14.3 \\
\hline 700 & 63 & 9 \\
\hline 800 & 64 & 8 \\
\hline 900 & 69 & 7 \\
\hline 1000 & 55 & 5.5 \\
\hline
\end{tabular}

Graph 3.4 Total accumulation of Arsenic by Phragmiteskarka

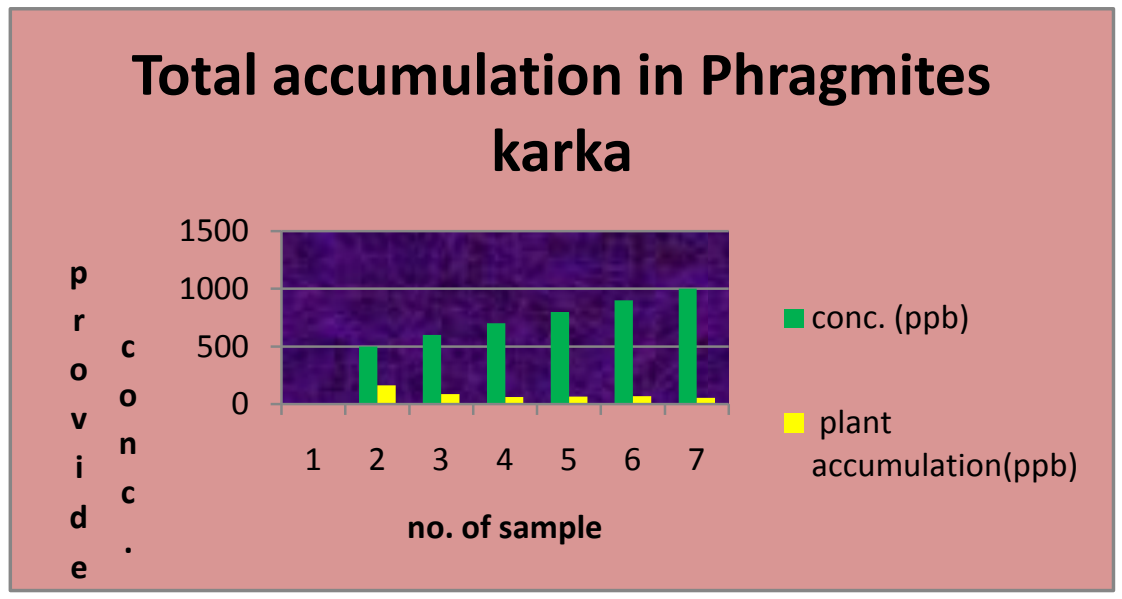

This indicatesthat total accumulation by the different parts of the plant body of test plant decreases after providing successive higher dose of Arsenic concentration from $500 \mathrm{ppb}$ to $1000 \mathrm{ppb}$ (Please see graph 3.4).

Fig 3.5 Showing pots planted with Phragmites karka of different concentration of arsenic.

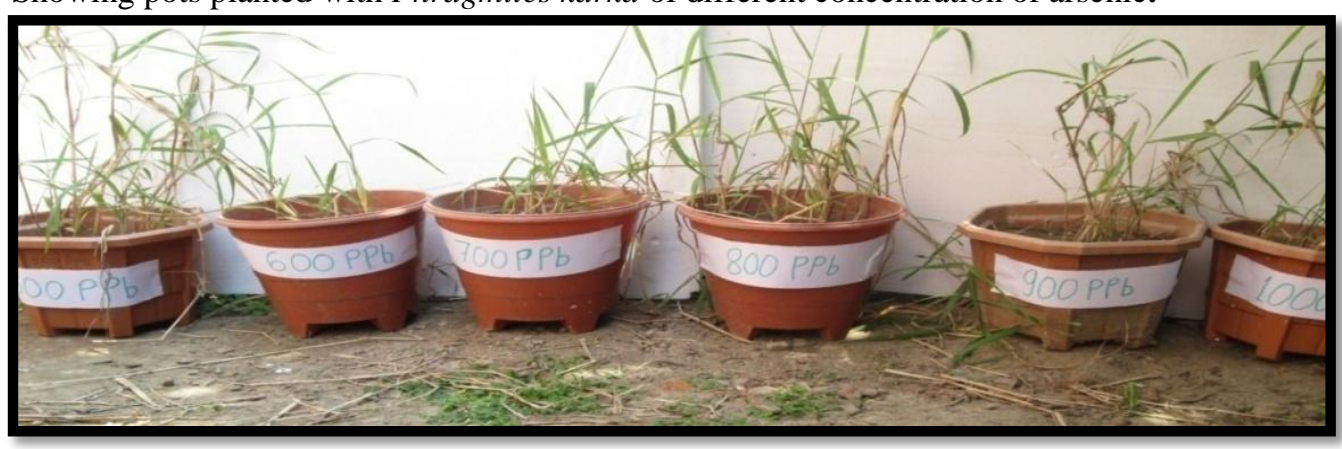

Fig 3.6 - Showing Tolerance Capacity (after providing concentration of $1400 \mathrm{ppb}$ )Tolerance capacity. 

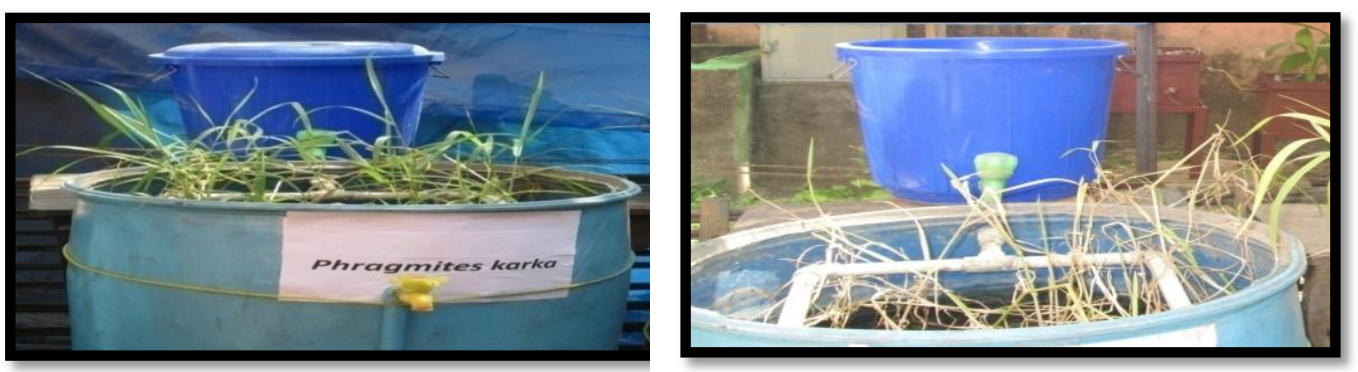

Tolerance capacity of Phragmiteskarka, Eiseniafetida and Microbes were investigated to check their growth on different concentration of arsenic.Plant were found to be survive on $1300 \mathrm{ppb}$ and $100 \%$ mortality was observed on $1400 \mathrm{ppb}$ (please see fig 3.6). In case of Eiseniafetida and Microbes higher tolerance observed.

\section{Conclusion}

The study suggests that the behavior of Phragmiteskarka alone with reference to tolerance of Arsenic containing solution is not uniform. At initial concentration from 500 to $800 \mathrm{ppb}$ of Arsenic input the retention of Arsenic by the plant has increased. Further $900 \mathrm{ppb}$ to $1300 \mathrm{ppb}$ the retention of arsenic by the test plant increased. It is observed that other concentration of $1400 \mathrm{ppb}$ was intolerable to test plant and its rendered toxicity, leading to death. Thus our studies conclude that the test plant was capable of arsenic retention up to $1300 \mathrm{ppb}$.Initially the accumulation was high as the toxicity of arsenic on test plant was not severe. When the concentration of Arsenic was increased the toxicity also increased, leading to decrease in Arsenic accumulation by the test plant.At more high concentration the test plant adapted itself to the Arsenic environment and that led to increase in Arsenic retention.At very high concentration (1400ppb) the toxicity became very severe and that led to death of the test plant.

\section{References}

[1]. Alkorta and C. Garbisu, Phytoremediation of organic contaminants (Bioresource Technol. 79, 2001) 273-276.

[2]. M. Bissen , F.H. Frimmel, Arsenic - a review. Part I: occurrence, toxicity, speciation, mobility, Acta Hydrochim, Hydrobiol, 31, 2003, 9-18.

[3]. E.J. Bouwer, A.J.B. Zehnder, Bioremediation of organic compounds putting microbial metabolism to work. Trends in Biotechnology(11, 1993) 287-318.

[4]. J. Brown, A. Colling, D. Park, J. Phillips, D. Rothery and J.Wright, Chemical cycles in the oceans, In: Bearman, G. (Ed.), Ocean Chemistry and Deep-Sea Sediments, (The Open University \&Pergamon Press, Buckinghamshire, 1991) 18-60.

[5]. S.L.Bruce, B.N. Noller,A.H. Grigg, B.F. Mullen, D.R. Mulligan, P.J. Ritchie, N. Currey and J.C. Ng, A field study conducted at Kidston gold mine, to evaluate the impact of arsenic and zinc from mine tailing to grazing cattle, (Toxicol. Lett,137, 2003) 23-34.

[6]. S. Buddhawong, P. Kuschk, J. Mattusch, A. Wiessner and U. Stottmeister, Removal of arsenic and zinc using different laboratory model wetland systems, Eng. Life Sci. 5, 2005, 247-252.

[7]. T. Cairney, Contaminated Land (Blackie, London. 4, 1993).

[8]. R.L. Chaney, M. Malik, Y.M. Li, S.L. Brown, E.P. Brewer, J.S. Angle and A.J. Baker, Phytoremediation of metals, Curr. Opin.Biotechnol. 8, 1997, 279-284.

[9]. R.R.H. Cohen, Use of microbes for cost reduction of metal removal from metals and mining industry waste streams, J. Clean. Prod. 14, 2006, 1146-1157.

[10]. P.F. Cooper P.F, G.D. Job, M.B. Green and R.B.E. Shutes, Reed Beds and Constructed Wetlands for Wastewater Treatment, (WRc Publications, Swindon. Wiltshire, 1996).

[11]. P.E. Flathman, D. Jerger, J.E. Exner, Bioremediation: Field Experience(Lewis, Boca Raton, FL, 1993).

[12]. C. Garbisu C and I. Alkorta, Basic concepts on heavy metal soil bioremediation, Eur. J. Min. Proc. and Environ. Protect. 3,2003, $58-66$.

[13]. C.Garbisu, J. Hernandez-Allica, O. Barrutia, I. Alkorta and J.M. Becerril, Phytoremediation: A technology using green plants to remove contaminants from polluted areas, Rev. Environ. Health. 17,2002, 75-90.

[14]. R.H. Kadlec and S.D. Wallace, Treatment Wetlands, (second ed. CRC Press, Boca Raton, FL, 2009).

[15]. D.B. Kosolapov, P. Kuschk, M.B. Vainshtein, A.V. Vatsourina, A. Wießner, M. Kästner M and R.A. Müller, Microbial processes of heavy metal removal from carbondeficient effluents in constructed wetlands, Eng. Life Sci. 4, 2004, 403-411.

[16]. M.D. Lagrega, J.C. Evans, C.O. Acuna, S.J. Zarlinski and D.S. Hall, Stabilization of acidic refinery sludge, Jour. of Hazard. Mater. 2-3, 1999, 169-187.

[17]. M.M. Lasat, Phytoextraction of toxic metals: a review of biological mechanisms, J. Environ. Qual. 31, 2002, 109-120.

[18]. B.K.Mandal and K.T. Suzuki, Arsenic round the world: a review. Talanta 58, 2002, 201- 235.

[19]. S.P.McGrath and F.Z.Zhao, Phytoextraction of metals and metalloids, Curr.Opin.Biotechnol. 14, 2003, 277-282.

[20]. S.P.McGrath, F.J. Zhao and E. Lombi E, Phytoremediation of metals, metalloids, and radionuclide, Adv. Agronomy 75, $2002,1-56$.

[21]. T. McIntyre, Phytoremediation of heavy metals from soil, Adv. Biochem. Eng. Biotechnol (78, 2003) 97-123.

[22]. R.B. Meagher, Phytoremediation of toxic elemental and organic pollutants, Curr. Opin. Plant Biol. 3, 2000, 153-162.

[23]. Meharg, New Phytol $(157,2003) 25-31$.

[24]. A.A. Meharg and J. Hartley-Whitaker, Arsenic uptake and metabolism in arsenic resistant and nonresistant plant species, New Phytol(154,2002) 29-43.

[25]. E.A. Nelson, W.L. Specht and A.S. Knox, Metal removal from water discharges by a constructed treatment wetland, Eng. Life Sci. 6, 2006, 26-30.

[26]. B.O. Olatunji, B.J. Deacon and J.S. Abramowitz, The Cruelest Cure? Ethical Issues in the Implementation of Exposure-Based Treatments, Cog. Behaviour, Sci. 2, 2009, 172-180. 
[27]. P.E. Flathman, D. Jerger and J.E. Exner, Bioremediation: Field Experience, (Lewis, Boca Raton, FL,1993).

[28]. L.M.Prescott, J.P.Harley andA.D. Klein, Microbiology, Fundamentals of applied Microbiology (2, 2002$) 1012$-1014

[29]. M. Scholz, B.H. Lee, Constructed wetlands: a review,Int. J. Environ. Stud, 62, 2005,421-447.

[30]. P.L.Smedley, H.B.Nicolli, D.M.J.Macdonald, A.J.Barros and J.O. Tullio, Hydrogeochemistry of arsenic and other inorganic constituents in groundwaters from La Pampa, Argentina, Appl. Geochem, 17 (3),2002, 259-284.

[31]. E. Smith, R. Naidu and A.M. Alston, Arsenic in the soil environment: a review. Adv. Agron. 64,1998, 149-195.

[32]. O.Weber, R.W. Scholz, R. Bu“ hlmann and D. Grasmu“ ck, Risk perception of heavy metal soil contamination and attitudes toward decontamination strategies, Risk Analysis (21, 2001) 967-977.

[33]. W.W. Wenzel, D.C. Adriano, D.Salt and R. Smith, Phytoremediation: A plant-microbe-based remediation system. Bioremediation of Contaminated Soils Agronomy(Monograph no. In: SSSA (Ed), 37, SSSA, Madison, WI, USA, 1999) 457-508.

[34]. Z.H.Ye,Z.Q. Lin, S.N. Whiting, M.P.de Souza and N. Terry N, Possible use of constructed wetland to remove selenocyanate, arsenic, and boron from electric utility wastewater, Chemosphere,(52, 2003)1571-1579.

[35]. E.A. Woolson, Arsenical Pesticides. (American Chemical Society, Washington DC, 176,1975).

[36]. J.G. Mueller, C.E. Cerniglia and P.H. Pritchard, Bioremediation of Environments Contaminated byPolycyclic Aromatic Hydrocarbons. In Bioremediation: Principles and Applications (Cambridge University Press, Cambridge, 1996) 125-194.

[37]. "Terra Nova's Rnvironmental Remediation Ren http://www.terranovbiosystems.com/science/remidiation-resourceshtml.Retrieved 2011-03-22.

[38]. K.P. Shukla, N.K.Singh and S. Sharma, Bioremediation: Developments, Current Practices and Perspectives, Genetic Engineering and Biotechnology Journal, 2010.

[39]. D.E.Salt, R.D. Smith and I. Raskin, Phytoremediation. Annu Rev Plant Physiol Plant MolBiol ,49, $1998,643-668$.

[40]. D.E.Salt, R.C. Prince, I.J. Pickering and I. Raskin, Mechanisms of cadmium mobility and accumulation in Indian mustard, Plant Physiol, 109, 1995,1427-1433.

[41]. D.E. Salt, R.D. Smith and I. Raskin, Phytoremediation. (Annu. Rev. Plant Physiol. Plant Mol. Raskin I, 1998).

[42]. D.E. Salt, R.D. Smith and I. Raskin, Phytoremediation of metals: using plants to remove pollutants from the environment,Curr.Opin.Biotechnol, 8, 1997, 221-226.

[43]. F. Navari-Izzo and M.F. Quartacci, Phytoremediation of metals, Tolerance mechanisms against oxidative stress (Minerva Biotec. $13,2001,) 73-83$.

[44]. C. Garbisu, J. Hernandez-Allica , O.Barrutia, I. Alkorta andJ.M. Becerril, Phytoremediation: A technology using green plants to remove contaminants from polluted areas, Rev. Environ. Health, 17, 2002, 75-90.

[45]. D. Mohan andC.U. Pittman, Arsenic removal from water/wastewater using adsorbents -a critical review. J. Hazard. Mater (142, 2007) $1-53$.

[46]. G. Sun, T. Saeed, Kinetic modelling of organic matter removal in 80 horizontal flow reed beds for domestic sewage treatment,Process Biochem $(44,2009)$ 717-722. 